\title{
Further evaluation of a claims-based algorithm to determine the effectiveness of biologics for rheumatoid arthritis using commercial claims data
}

\author{
Jeffrey R Curtis¹, Benjamin Chastek², Laura Becker², David J Harrison³, David Collier³, Huifeng Yun ${ }^{4}$ and George J Joseph ${ }^{3}$ \\ See related research by Curtis et al., http://arthritis-research.com/content/13/5/R155, and related editorial by Kim and Solomon, \\ http://arthritis-research.com/content/13/5/129
}

\begin{abstract}
Background
As more biologics are approved, there is increasing interest in comparative effectiveness research (CER). Health insurance claims databases contain information about outpatient visits, hospital discharges, procedures, and outpatient pharmacy dispensing but seldom contain clinical outcomes. In a previous issue of Arthritis Research \& Therapy, we presented an algorithm that assessed the clinical effectiveness of rheumatoid arthritis (RA) biologics which used Veterans Affairs (VA) claims data and which was validated against the DAS28-ESR (Disease Activity Score 28 using erythrocyte sedimentation rate) [1]. The algorithm had a sensitivity of $72 \%$ ( $95 \%$ confidence interval $(\mathrm{CI})=67 \%$ to $77 \%$ ) and a specificity of $91 \%$ (95\% CI $=89 \%$ to $93 \%$ ). In an editorial in the same issue, Kim and Solomon [2] commented the following: 'a claims-based effectiveness algorithm with acceptable performance characteristics across different data settings will be a powerful and desired tool for CER of RA. Such an algorithm will enable large-scale, population-based studies comparing the effectiveness of different DMARD [disease-modifying antirheumatic drug] regimens. Such studies will facilitate head-to-head comparisons, supplementing typical randomized controlled trials and prospective registries that usually include disease activity. Whether the algorithm will have a similar performance in other claims databases therefore needs to be further examined. We performed an independent analysis to evaluate the algorithm's positive predictive value (PPV) in a commercial claims data source compared with a clinical gold standard.
\end{abstract}

*Correspondence: jcurtis@uab.edu

'Division of Clinical Immunology and Rheumatology, University of Alabama at Birmingham, 510 20th Street South, FOT 802D, Birmingham, AL 35294, USA Full list of author information is available at the end of the article

\section{Methods}

Data came from a previous comparative effectiveness study linking outpatient medical records from multiple US institutions and physician practices to commercial claims data from OptumInsight (Eden Prairie, MN, USA) [3] that evaluated the effectiveness of etanercept (ETN), adalimumab (ADA), and infliximab (INF) in biologic naïve adult RA patients persistent on their initial biologic for at least 1 year from 2006 to 2008. Two teams of two rheumatologists reviewed each medical record and categorized clinical change around 1 year as 'much better,' 'better,' 'no change,' 'worse', or 'much worse'. For this study, the biologic was considered effective if the patient was rated as 'better' or 'much better'. Sensitivity, specificity, and negative predictive value could not be determined, because patients switching biologic agents were excluded from the original study. The PPV compared the classification from the algorithm to the rheumatologist rating. Different compliance thresholds with the biologic medications used by the algorithm were evaluated as sensitivity analyses.

\section{Result}

The majority (76\%) of the 429 patients in the study were female, and the mean age was 51 years. The PPVs were $86.6 \%$ in the primary analysis and $86.5 \%$ in sensitivity analyses, similar to that of the original algorithm using VA data. PPV did not differ significantly by biologic $(P>0.2)$ : INF $(\mathrm{PPV}=95 \%)$, ETN $(\mathrm{PPV}=86 \%)$, and ADA $(\mathrm{PPV}=85 \%)$.

\section{Conclusions}

This previously published administrative claims-based effectiveness algorithm had a high PPV across commercial claims data and VA data. This algorithm may be useful in evaluating the effectiveness of biologic agents by administrative claims data in future studies. 


\section{Abbreviations}

ADA, adalimumab; $\mathrm{Cl}$, confidence interval; ETN, etanercept; INF, infliximab; PPV positive predictive value; RA, rheumatoid arthritis; VA, Veterans Affairs.

\section{Competing interests}

The authors declare that they have no competing interests.

\section{Acknowledgments}

JRC receives support from the National Institutes of Health (AR053351) and the Agency for Healthcare Research and Quality (R01HS018517) and reports grants or consulting work or both with Roche (Basel, Switzerland)/Genentech (South San Francisco, CA, USA), UCB (Raleigh, NC, USA), Centocor (Horsham, PA, USA), Corrona (Southboro, MA, USA), Amgen Inc. (Thousand Oaks, CA, USA), Pfizer Inc (New York, NY, USA), BMS (New York, NY, USA), Crescendo (South San Francisco, CA, USA), and Abbot (Abbott Park, IL, USA). This research was funded by Immunex Corporation (Seattle, WA, USA), a wholly owned subsidiary of Amgen Inc., and by Wyeth (Madison, NJ, USA), which was acquired by Pfizer Inc in October 2009. HY has received research support from Amgen Inc. for unrelated work. BC and LB are employees of Optumlnsight. DJH, DC, and GJJ are employees of Amgen Inc.

\section{Author details}

'Division of Clinical Immunology and Rheumatology, University of Alabama at Birmingham, 510 20th Street South, FOT 802D, Birmingham, AL 35294,

USA. ${ }^{2}$ Optumlnsight, 12125 Technology Drive, Eden Prairie, MN 55344, USA

${ }^{3}$ Amgen Inc., One Amgen Center Drive, Thousand Oaks, CA 91320, USA
${ }^{4}$ Department of Epidemiology, School of Public Health, University of Alabama at Birmingham, 1700 University Boulevard, Birmingham, AL 35294-0013, USA.

\section{Published: 8 March 2013}

\section{References}

1. Curtis JR, Baddley JW, Yang S, Patkar N, Chen L, Delzell E, Mikuls TR, Saag KG, Singh J, Safford M, Cannon GW: Derivation and preliminary validation of an administrative claims-based algorithm for the effectiveness of medications for rheumatoid arthritis. Arthritis Res Ther 2011, 13:R155.

2. Kim SY, Solomon DH: Use of administrative claims data for comparative effectiveness research of rheumatoid arthritis treatments. Arthritis Res Ther 2011, 13:129.

3. Bonafede RP, Pearson D, Babich J, Chastek B, Becker L, Watson C, Chaudhari S, Harrison DJ, Gandra SR: Comparative effectiveness analysis of TNF-blockers in rheumatoid arthritis (RA) patients in a real-world setting. Value in Health 2011, 14:A1

doi:10.1186/ar4161

Cite this article as: Curtis JR, et al: Further evaluation of a claims-based algorithm to determine the effectiveness of biologics for rheumatoid arthritis using commercial claims data. Arthritis Research \& Therapy 2013, 15:404. 